\title{
Primary Lymph Sac
}

National Cancer Institute

\section{Source}

National Cancer Institute. Primary Lymph Sac. NCI Thesaurus. Code C34262.

Any of six primary lymph sacs (two jugular lymph sacs, two iliac lymph sacs, one

retroperitoneal lymph sac and one cisterna chyli) found during the embryonic period that are the first precursors of lymph node and lymph vessel development. 